\title{
Traps for collection of the insects in Brazil.
}

\author{
Carlos Henrique Marchiori
}

1 Ins tituto Federal Goiano

One of the best ways to study insects is to take excursions to observe their habits and collect them. Handling and collection reveal information through direct observation, which is often not recorded in scientific books or articles.All collection techniques tend to be more or less selective.

To remedy this difficulty, one must then use different techniques to collect greater diversity and quantity. To standardize collections, some common procedures are required, such as selecting areas in reserves or ecological stations or research stations, which have not yet been significantly altered by man and have minimal log istical infrastructure; have facilities for transportation of material; use the same techniques, same number of equipment, same collection effort, and have a team of trained personnel to set up traps and sort material.

These four types of traps are important for collecting insects of the Orders Diptera and Hymenoptera.

Traps:

1- Moericke Trap (yellow bowl, tray or dish).

2- Malaise Traps.

3- Metal Container Traps.

4- Pitfall type traps. 


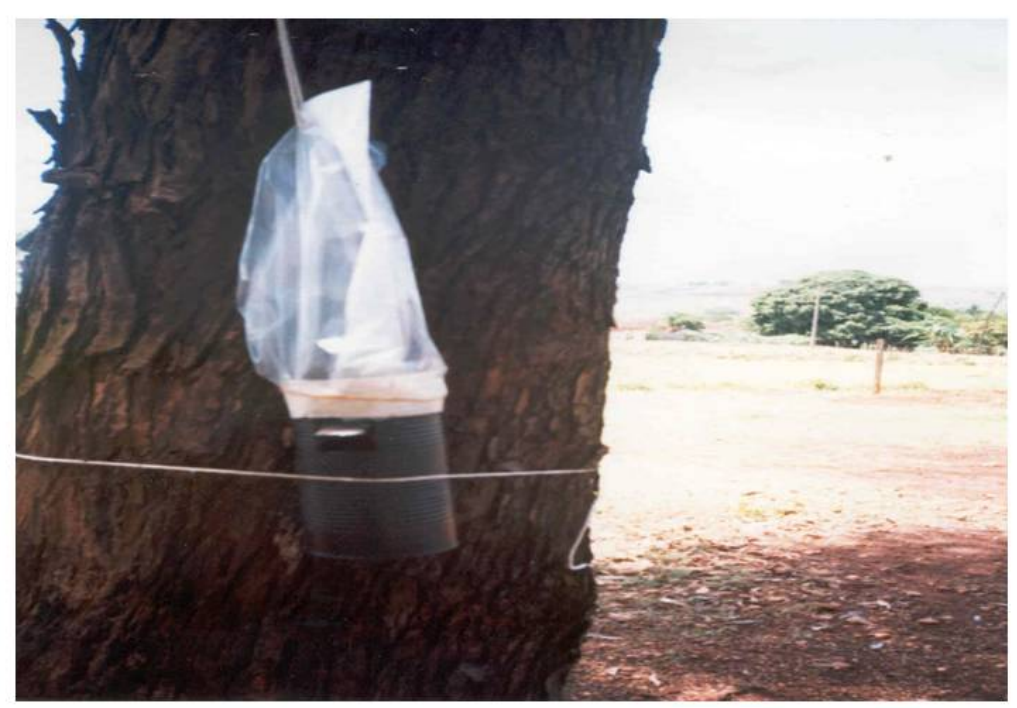

3- Metal Container Traps.

Figure

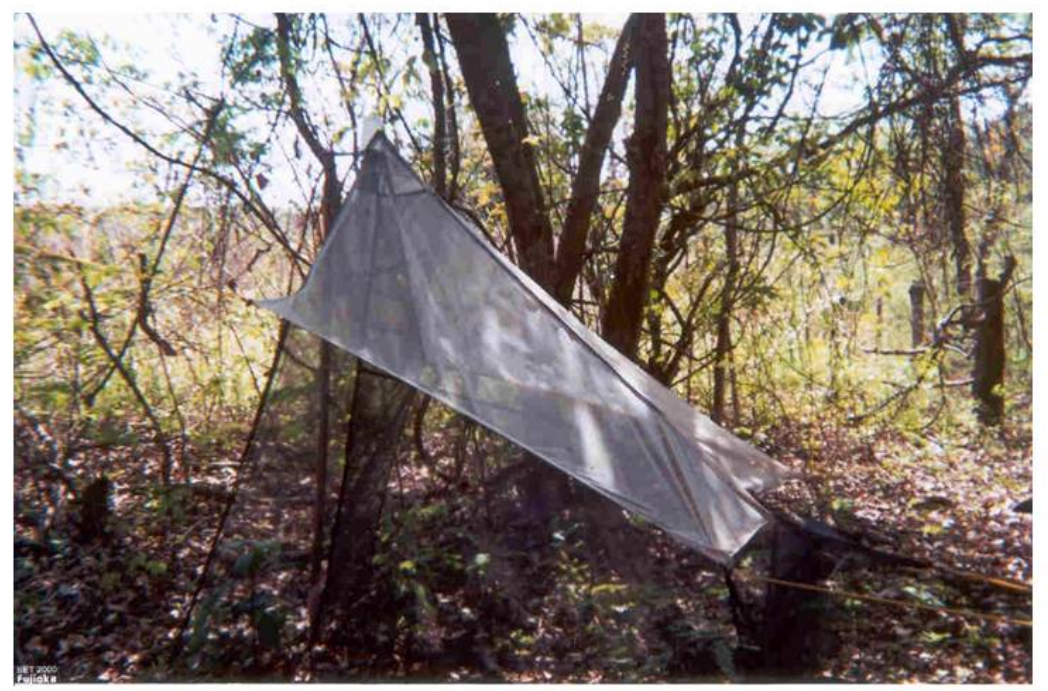

2- Malaise Traps. 


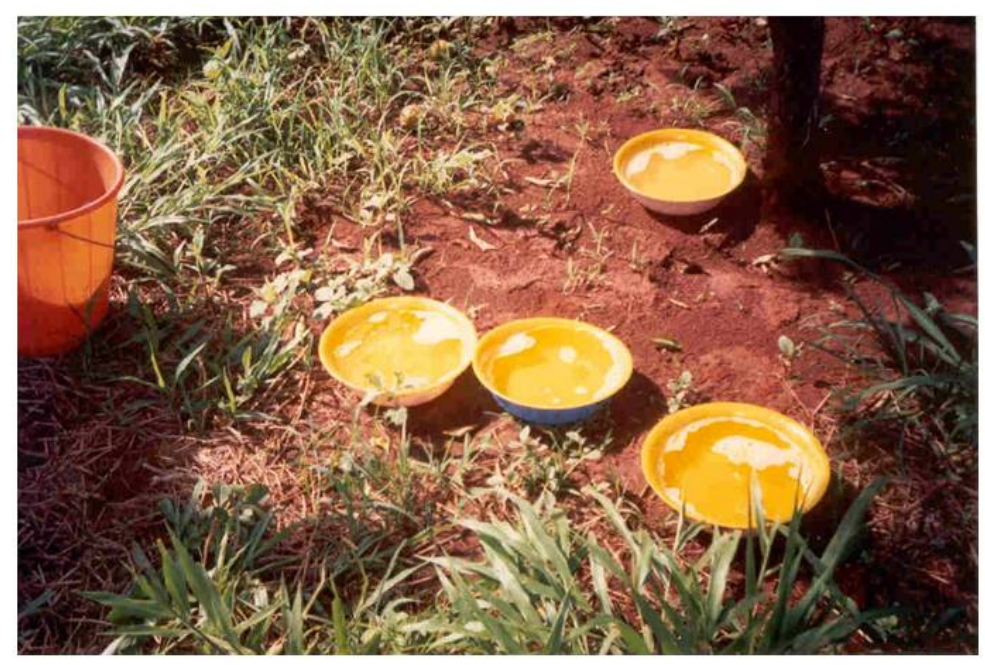

1- Moericke Trap (yellow bowl, tray or dish).

Figure

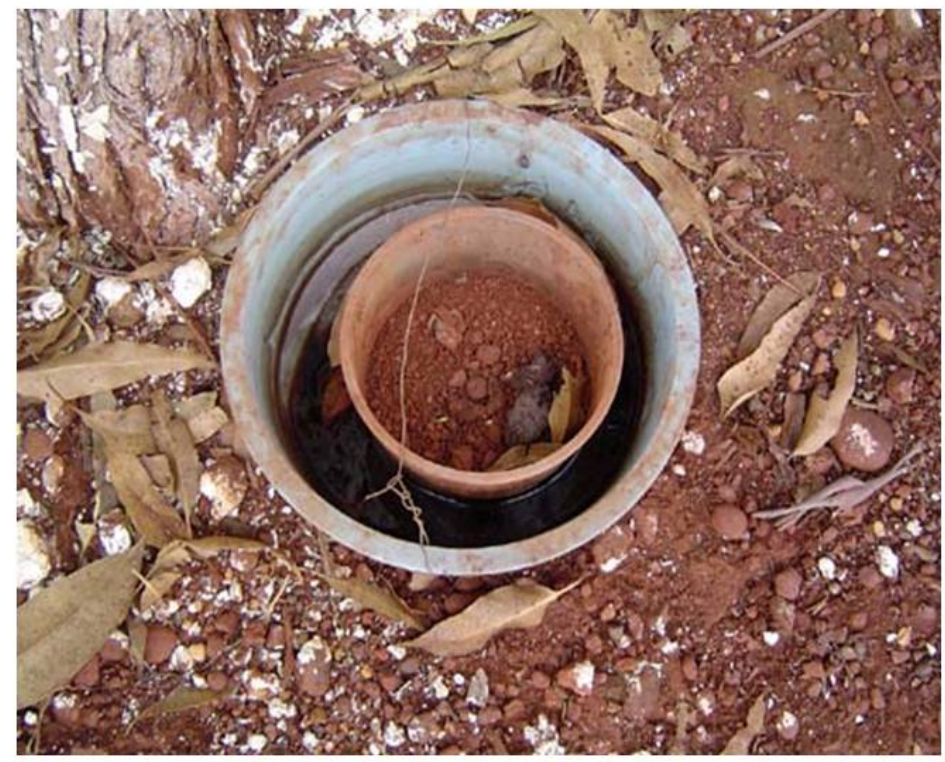

4- Pitfall type traps. 